\title{
A year in the life of Canadian Forces Health Services
}

$\mathrm{N}$ ovember is a month of remembrance, and this year there is much to remember for our military health care personnel, and for the Canadian Forces. This past year, we have moved our small field hospital from Kabul in northern Afghanistan to Kandahar in the south, joining, then replacing, an already-existing American one, while expanding it to a full-service multinational facility with partners from the United Kingdom, the Netherlands, the United States and Denmark. We deployed a CT scanner and full digital imaging suite for the first time, initiated a teleradiology capability, and have been receiving and treating casualties throughout. Ensuring first-class care for coalition soldiers from point of wounding to home in Canada is a "no-fail mission," and our health care personnel have risen to the challenge. We are relearning old lessons, grappling with new issues and taking combat casualty care to new levels of excellence. Thanks to improve-

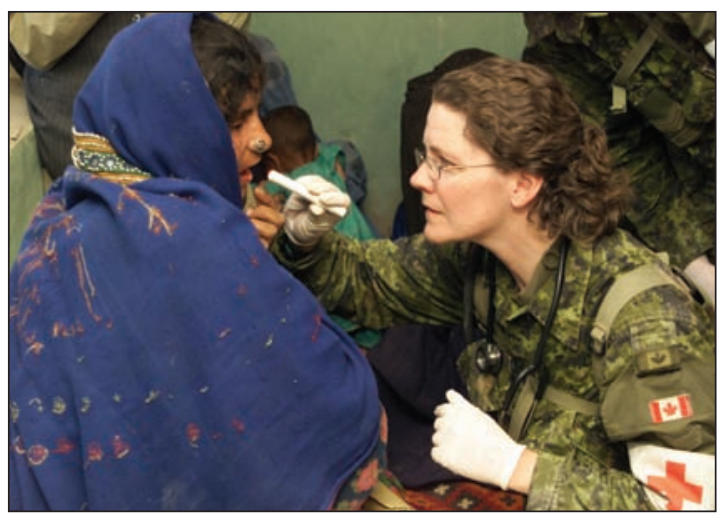

Courtesy of the Canadian Forces Image Gallery, National Defence. Reproduced with the permission of the Minister of Public Works and Government Services, 2006. accepting the unlimited liability of being sent into harm's way, and we owe them the best of care. To date, I believe we have provided it, and I have never been prouder to be a member of the Canadian Forces Health Services.

Our hospital staff and surgical teams have routinely performed small miracles in the most difficult circumstances, saved many lives and limbs and spirits, broken new ground in field medicine, and earned the respect and admiration of NATO, our coalition partners and the Afghan people. In particular for me, it has been extremely rewarding to have played a part in enabling our medics to deploy with an enhanced level of confidence engendered by state-of-the-art training and to see advances like QuikClot, the Israeli advanced compression field dressing and the Trauma Combat Casualty Care Course saving lives every day. As health care professionals, we all give of ourselves for our patients. These medics do so in the most arduous of circumstances, under the ments in combat-related first aid, helicopter evacuation and personal protective equipment, more casualties are reaching the field hospital alive. They are globally more complex and, once their condition is stabilized, must be evacuated quickly through the US Army Hospital in Germany. Managing aeromedical evacuation of intensive care patients from Germany to Canada is just one of the capabilities we are now exercising routinely, and doing it well. We have accomplished this in spite of severe shortages in uniformed personnel and in the face of sequential downsizing and "outsourcing" of military medical services.

Since closing our military hospitals over the past decade, we are also rediscovering our essential links with the Canadian civilian health care sector. We have military clinicians embedded in facilities across the country, and our military clinics employ many civilian care providers. The interchange and mutual understanding resulting from this arrangement have stood us in good stead as we have moved to a whole new paradigm in terms of care of our soldiers. It has been truly heartwarming to experience the cooperation and effort of our civilian colleagues Canadawide as these soldiers come home needing very special care.

They are very special patients, these soldiers. I have always known this, but seeing so many of them come home wounded has taken my appreciation of this to a different place. They are our children, our spouses, our friends, and they perform their duty to Canada in exemplary fashion, fully same conditions and in the same danger as our combat soldiers, and they are revered by their fighting comrades. They are what makes it possible for the field hospital to accomplish wonderful feats, because they get the casualties there alive. To $\mathrm{Cpl}$ Eykelenboom and $\mathrm{Cpl}$ Arnold, our first medics killed in action since the Korean War, and to MCpl Franklin, who lost both legs in a suicide bombing and is now busy passing on his expertise to other medics, our deepest thanks for making the ultimate sacrifice in the service of your patients and your country, and for embodying the highest ideals of service. You are an inspiration to us all.

In closing, I would like to thank, on behalf of Commodore Kavanagh, our Director General Health Services, and Brigadier-General Jaeger, our Surgeon General, all the civilian health care providers who have been of such assistance to us during these trying times. Your support has been pivotal, and will continue to be. Canada has one of the world's best health care systems, and it is proving itself ready and able to assist us in our hour of need.

\section{Maureen Haberstock}

Health Services Operations

Canadian Forces

Ottawa, Ont.

This article has been peer reviewed. 